\title{
The hook of the humanitarian medicine: an exciting adventure in Congo
}

\author{
Luis Chiva, Madrid, Spain
}

During the past 2 years, the Department of Gynecology of University of Navarra has had the opportunity to carry out a humanitarian medical project in the heart of Africa.

More specifically in the Monkole Hospital, a Catholic institution located in a suburb of Kinshasa, Congo, called Montgafula. The cervical cancer rate in Congo is strikingly high, similar to other African countries. Both cervical and breast cancer rank among the most common cancer in women in this region. Currently, there are no screening programs for cervical cancer for these women. In fact, often the clinical manifestation of cervical cancer means the death of the patient. I have had the great fortune to be accompanied by 10 medical students on several missions, and we have worked intensely to develop sustainable screening programs for cervical cancer. We screened approximately 500 patients in each campaign. Just last summer we diagnosed a total of seven cervical cancers and 54 pre-neoplastic lesions, nine of which were highgrade dysplasia. At the same time, we have developed a research project to validate the efficacy of acetic acid and Lugol dye in the screening of cervical cancer.

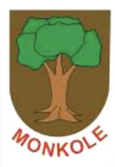

\section{DEPISTAGE DU CANCER DU COL UTERIN A MONKOLE (GRATUIT)}

\section{DR. TENDOBI (MONKOLE) EN COLLABORATION AVEC DR. CHIIVA ET DR. JURADO (UNIVERSITE DE NAVARRE) TOUS LES JOURS SUR RENDEZ-VOUS} VOIR RECEPTION CHME CONTACTS 089000385/0890003032

Figure 1 Local announcement placed in several locations in the neighbors close to Monkole.

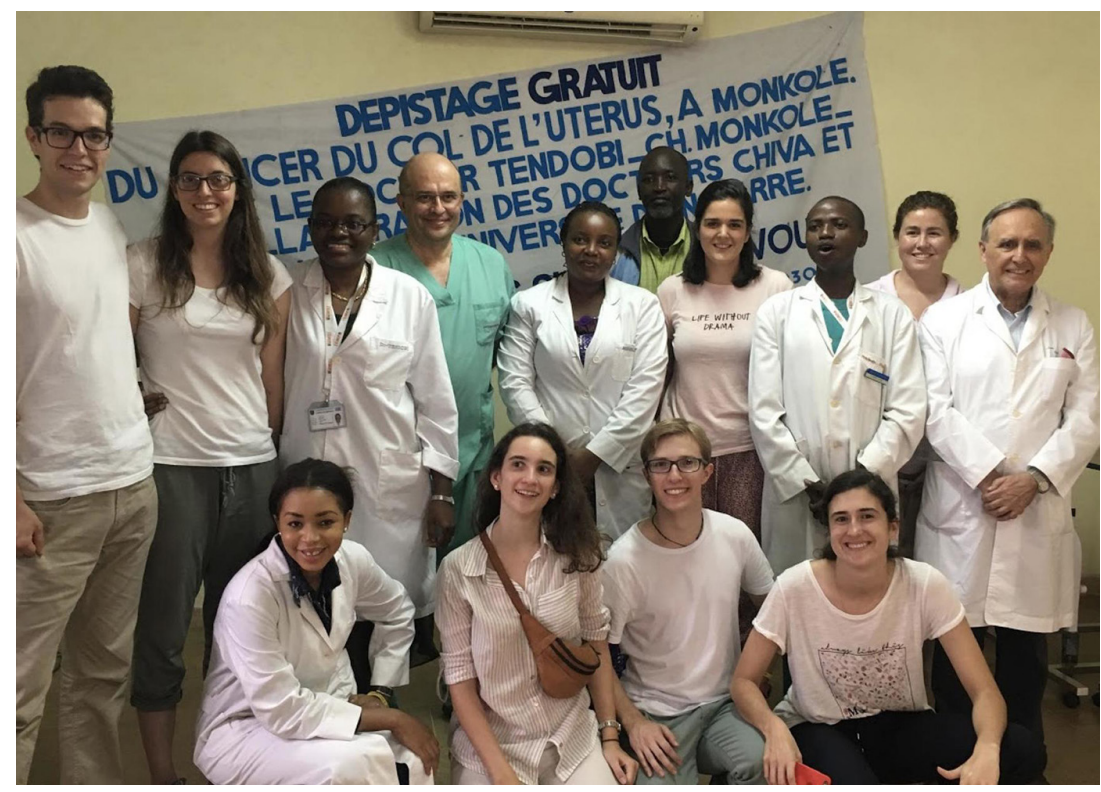

Figure 3 The Screening Group just before starting the work.
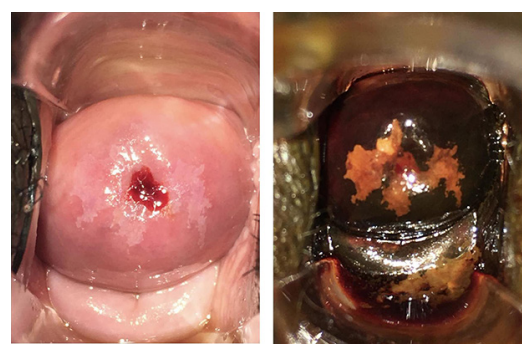

Figure 2 Positive visual inspection after acetic acid and Lugol. Pictures were taken with our mobile phones for evaluation.

To carry out this project, during the weeks leading up to the visit, we announced a free prevention campaign in the contiguous neighborhoods. In the announcements, a contact telephone number was offered to patients so they could register for the program (figure 1). Before starting the screening test, each woman was invited to read an informed consent. When French was not understood, Lingala was the alternative language. We took this opportunity to disseminate education material to the community on basic aspects of the human papilloma virus, as well as the importance of periodic screening.

The methodology of the campaign was very simple. First, a questionnaire was completed detailing basic demographics and symptoms. Then, a pelvic examination was performed and a cervical smear using liquid-based cytology and HPV DNA detection was performed. This material was returned to Spain for analysis. Subsequently, $5 \%$ acetic acid was applied to the cervix and a picture of the uterine cervix was taken with a mobile phone. Then the Lugol dye was applied and a second picture was taken. Images were evaluated by Dr Chiva and local doctors, in order to obtain a final assessment on visual inspection: positive or negative. Those patients in whom special visual with acetic and/or Lugol was positive, were treated 
immediately with cryotherapy by means of two applications of liquid nitrogen.

When a clinical carcinoma was suspected, we performed biopsies that were brought to Spain for evaluation. All patients underwent a clinical staging following the FIGO guidelines for cervical cancer. Our preliminary results showed a $18 \%$ rate if HPV infection and $11 \%$ rate of abnormal cytological lesions. Interestingly among high grade lesions, HPV genotype 18 was not found in any case. Finally, considering as gold standard any abnormal suspicious cytological finding (ASCUS, LGSIL or HGSIL): sensitivity, specificity, and negative predictive value were $66 \%, 87 \%$, and $94 \%$ respectively.

At the end of the campaign, three local physicians were trained for cervical cancer screening (figure 2) and a sustainable screening office was open in the center. Our medical students (figure 3) had an incredible educational and human experience that will most probably impact their professional life very positively. I have to confess that it has been a deeply rewarding experience.

Matongo Mingi (in Lingala: thank you very much)
Correspondence to Luis Chiva, Department of Gynecology, Universidad de Navarra, Madrid, Spain; Ichiva@unav.es

Provenance and peer review Not commissioned, externally peer reviewed;

C IGCS and ESGO 2019. No commercial re-use. See rights and permissions. Published by BMJ.

D Check for updates

To cite Chiva L. Int J Gynecol Cancer 2019;29:221:221-222..

Accepted 17 October 2018

Int J Gynecol Cancer 2019;29:221:221-222.

doi:10.1136/ijgc-2018-000002 